\title{
Self-representations of College English Teachers' Professional Identities
}

\author{
Zhidong Gao, a ${ }^{1,}$ Xiu $\mathrm{Li}^{2, b}$, \\ ${ }^{1}$ School of Foreign Languages, Yan'an University, Yan'an, Shaanxi Province, P. R. China, 716000 \\ ${ }^{2}$ School of Foreign Languages, Xinjiang University, Urumqi, Xinjiang, P. R. China, 830046 \\ avictorzd@163.com; ${ }^{b}$ 270855728@qq.com
}

Keywords: internationalization; teacher professional identity; teacher burnout; representation

\begin{abstract}
English teachers are bearing the brunt of international shocks and impacts partly due to the accessibility of language. The presentation of their profession is significant to realization of teaching effectiveness. The present study attempts to analyze the role value, professional value, and professional sense of belonging and professional behavior tendency from a structural perspective, and teacher burnout, turnover intention and job satisfaction from a relational perspective. The results indicate that college English teachers have relative strong teachers' professional identities, significant differences in educational backgrounds and school levels, without obvious differences between ages, genders and professional titles. Relevant teaching suggestions are provided.
\end{abstract}

\section{Introduction}

Integration and virtualization have caused comparison and contradiction among different nations and regions of the modern society. In the realm of education, teachers are influenced significantly. Due to the accessibility of language, English teachers are bearing the brunt of international shocks and impacts. How English teachers present their profession is significant to realization of teaching effectiveness, and the improvement of teaching quality. Thereby, the essential issue of this study is to explore university English teachers' psychological states to reveal how they perceive their profession.

English, as the lingua franca, is seen as the most significant contributing factors for internationalization. Internationalization of education first means Englishization. "No English, no internationalization" [1]. With the spread of English as an international language for cross-cultural communication, attentions have turned to the non-native English teachers' positive contribution to teaching English for international intelligibility and communication. What's more, with the spreading of English as an international language (EIL), teachers' sense of professional identity has been realigned accordingly. Specifically, English teachers should work as a positive linkage to prepare students for internationalization programs and help to create English courses in accordance with the requirements of internationalization in modern education.

This internationally-oriented trend irreversibly precipitate teachers facing with the challenges and changes, encompassing utilizing all the possible resources worldwide, facilitating with all the advanced technologies, and satisfying to the benchmarks of educational achievements in evaluated system in the process of internationalization. Meanwhile, most of the English language classrooms are still dominated by the teachers' linguistic knowledge. Many English teachers entering the profession still choose the traditional way of teaching. They are more concerned about the intellectual development of students and academic excellence.

Therefore, English teachers are undergoing the more heavily pressure, they are not only responsible for the above-mentioned items in China, but also inevitable to bear the pressure and the conflict between the requirements of internationalization and the evaluated systems and curriculum policies carried out in the current situation.

Facing with the aforementioned shocks and conflicts, English teachers are suffering from more heavily stress and pressure, which may push them begin to re-introspect themselves and realign their profession. 
As different representations of profession are generally oriented towards personal and reflected psychological states, how English teachers present their profession is significant to explore the psychological states as well as the existing issues from teachers' perspectives. How teachers' perceive their profession is important to professional development, which serve as the internal assurance to realize teachers' professional development and play a crucial significance in advancing the successful realization of curriculum reforms and teaching activities.

Thus, the study attempted to explore the psychologies and psychological states of English teachers, so as to finding ways to deal with the psychological issues, improve the level of professional identity and to realize teaching efficacy finally.

\section{English Teachers' Professional Identity (TPI)}

Identity is regarded as a professional group in the attitude, knowledge, skills, values and beliefs of members [2]. Teachers, as the special groups, are required to carry out to abbey this rule without exceptions. In addition, in the realm of education, it is a common sense that professional identity is regarded as teachers' professional identity. English teachers share the three categories of self-identity, role-identity and social-identity. Self-identity emphasizes that the development of identity is unified and consecutive subjective feeling [3]. Role-identity emphasis how social role people played defined to themselves, providing a platform for social members to communicating. Socially, identity is viewed more often as to form social perspectives rather than personal angles. Self-identity originated from psychoanalysis, role identity from microsociology, and social identity from social-psychology. They are interpreting “self” from different perspectives.

TPI was regarded as "who or what someone is, the various and diversity meanings people can attach to themselves or attributed by others" [4]. It is constantly reflecting professional group's attitude, personal value, beliefs, skills and knowledge. Studies concentrate on either the process of becoming, such as developing teachers’ professional identity.

\section{Research Paradigms}

\subsection{Structural Study.}

Four dimensions of the structure of TPI are represented as centrality, valence, solidarity, self-presentation. Centrality means the significance and the inter-connection; valence presents the attraction and values of TPI; solidarity shows the preparation of sharing dealing with the destiny; and self-presentation is the willingness to be a teacher. Professional value means positive understanding and evaluating of teacher profession; role value indicates that positive understanding and evaluating of the significance of role of teachers, and presenting the willingness to answer who we are from the perspective of teacher roles. Professional sense of belonging shows teachers has the sense that they are belonging to the group of teachers and the have the same emotional experience. Professional behavior tendency means teachers have behavior to finish works and serve to responsibility. In addition, they have the tendency to improve unrequited professional work efficacy.

\subsection{Relational Study.}

TPI is correlated with the level of turnover intention, teacher burnout, job satisfaction, and teacher professional development. In particular, teacher professional development is explored to correlate with TPI positively, and TPI can influence self-efficacy, motivation, promise and job satisfaction of teachers in verse [5], which is a psychology basis of professional development and a core for an effective teacher. The crisis of TPI can resulted in the career stagnation, professional direction lost, lower efficiency and burnout. Identity crisis has intrinsic connection with teacher burnout negatively, and teacher burnout is a result of and outward signs of professional identity crisis. On the other hand, the level of TPI could be predicted turnover intention and there is significantly negative correlation between TPI and turnover intention. 


\section{Theoretical Framework}

\subsection{Internationalization of Education.}

Internationalization is becoming an irreversible trend in the field of education, enhancing students' understanding of various culture and knowledge, strengthening recognition of their own culture. It is a cross-border cultural exchange and can foster deeper understanding between countries and enhance knowledge production.

One important precondition for internationalization is that nations remain the basic unit. The relationship and in-depth community among different nations present increasingly necessary and important. And the internationalization of education is one of the most important parts. Commonly, the internationalization of education is basically involved the internationalization of the faculty, the courses, or degree programs, and the students. The essence of international education is to promote the international understanding under the prerequisite of safeguarding the country's benefit, and to develop international communication and cooperation in education.

Approaches to deal with internationalization in the field of education could be conducted into national level and institutional level [6]. At the national levels are expounded in four aspects: rationales, programs, policy and strategies. Policies concern variety of sectors including education, foreign affairs, technology, culture, science, and trade. Approaches at institutional levels have been interpreted as activity, outcomes, rationales and process. In a certain sense, facing with the inevitable worldwide education, English teachers are required to cultivated international person. The internationalization of education is an inevitable and ongoing trend, and this theory can be used as reference for universities on such aspects as helping to understand "what is internationalization of education", preparing for "what's the requirements of internationalization" and working out "How to cope with the internationalization trend".

\subsection{Social Cognitive Career Theory.}

Social cognitive career theory (SCCT) provides a relatively new method to understand the "dynamic processes and mechanism” through three steps: academic and career interests develop, educational and career-related choices, academic and career performance outcomes. These intricately and complexity variables are prominent as the centrals and served together as the most basic building blocks of SCCT, they are self-efficacy, outcome expectations, and choice goals.

Outcome expectation refers to "the beliefs in terms of the outcomes and consequences towards the various performing behaviors", including physical, social and self-evaluative forms [7]. Self-evaluated is somehow connected with one's capability to perform as the required given behaviors, while outcome expectations are concerned tightly with the anticipated outcomes of that given behavior. Choice goals embody the intention to engage in a particular action or serious of actions, which present the final person achievements in terms of cognition [8]. Consistently, choice goals, to some extent, are regarded as the antecedent to actual behavior proximately. Meanwhile, it is significant to concentrate that the cognitive-person variables are not operate and function in isolation.

On the basis of SCCT, both self-efficacy and outcome expectations are present to predict vocational interests significantly. Environment factors can influence the cognitive-person variables, and they can impact the self-efficacy and outcome expectations concerning with the complex and various personal behavioral choices and also the behavioral choices they will make ultimately.

\subsection{Career Stages Models.}

Burden's model characterizes teachers' development as a set of three consecutive stages which are closely connected to individual teaching experience [9]. Teachers pass through three stages known as survival, adjustment, and mature stages [10].

Teachers in their first stage learn what and how to teach, having limited knowledge of teaching activities, lacking confidence, and hesitating to try out new method [11]. In the second stage they learn a great deal about planning, organization, curriculum, and methodology. In the third stage teachers are expected to acquire a good command of teaching, fully develop an understanding of 
their teaching environment, and they recognize their students as individuals having unique characteristics and differences. Although these stages might be the representatives of teacher's development, they do not necessarily apply to every single teacher in the same way[12].

\section{Research Design}

Research Question. According to the basis of the internationalization of education, social cognitive career theory and identity theory, through documents analysis, questionnaires and interviews, the study attempts to explore university English teachers' perception of their profession in terms of structural study and relational study. Therefore, the research question addressed in this paper is: How university English teachers present their professional identities from the perspective of internationalization?

To be more specific, the following seven aspects are submitted: (1) role value, (2) professional value, (3) professional sense of belonging, (4) professional behavior tendency, (5) teacher burnout, (6) turnover intention, (7) job satisfaction.

Research subjects. The research subjects are 60 university English teachers, 12 are new comers in teaching and 48 are experienced teachers.

\subsection{Instruments.}

Questionnaires. Three questionnaires are used. The first one intended to investigate the general picture of teachers' professional identity, including 18 items about professional value, role value, professional belonging, and professional behavior tendency. The second is the commonplaces of burnout research containing three dimensions, emotional exhaustion, dehumanization and diminished personal accomplishment. The third intended to measure the level of turnover and teachers' intention to change to another job.

Interview. The interviews, as a complementary method, attempt to concentrate on the teachers' satisfaction, and their attitudes toward educational internationalization.

\subsection{Data Collection and Analysis}

\subsubsection{Structural studies.}

General presentations. It was found that in the TPI, M=4.02, Min is 2.94, Max 4.79, Std. .486, revealing that there are differences among the participants in different items. The mean of role value (RV) holds the highest position, $M=4.346$, followed by professional value (PV) 4.045, professional sense of belonging (PSB) 3. 826, and professional behavior tendency (PBT) 3. 621.

Characteristics of TPI. In was found that in all the four aspects, the gender differences were significant, with the Sig. value in ANOVA as .166(RV), .927(PV), .629(PSB), .034(PBT), and .283 (TPI). In age differences, the Sig. value concerning the five aspects are.030, .195, .873, .936, and .406 in the ages of younger than 29, 30-39, 40-49, and 50-59 respectively. The data presented that there are no obvious differences of professional identity among different age levels. Meantime, for the P value of the four dimensions of TPI indicates that there are no obvious differences among the dimensions of professional value, professional sense of belonging and professional behavior tendency.

Educational background. The value of TPI (Sig. $=.002$ ) indicates that there are significant differences of professional identity in terms of educational backgrounds. The highest obvious differences professional sense of belonging and the lowest is role value, which can be listed as professional sense of belonging professional values $>$ professional value $>$ professional sense of belonging >role values. Besides, professional identity of university English teachers with lower educational background who will has the stronger TPI than those teachers with higher educational backgrounds. According to the findings of the aforementioned analysis of mean level of role value, it always possesses a relative higher position than others and rarely affected by other foci. The educational results are proofs of there are higher level of role values among English teachers, which indicates that they have a strong sense of teachers' role value. 
Professional titles. The value of Sig. is .056, which indicates that there are no differences of TPI among different professional titles. In addition, it is easy to find out that the average value of university English teachers in high teaching positions are on the higher TPI than those teachers in the lower teaching positions; professional identity of them with high teaching positions are relatively stronger than those having a lower teaching positions. Professional values (Sig. =.056) represents that no significant differences in terms of professional values, and teachers with different positions owning the similar sense of identity. Otherwise, the Sig. of professional senses of belonging is 0.72 , which explore that there is no obviously significant. However, the one dimension that of professional behavior tendency has obvious differences on basis of the tabulated data.

\subsubsection{Relational Study}

Teacher Burnout. Professional identity is significant to make a concentration on the teacher's profession in three core dimensions, emotional exhaustion (EE), depersonalization (D), and feelings of decreased personal accomplishment (PA). The present study code the questionnaire: "strongly agree" code as 5, "agree” as 4, "neither agree nor disagree” as 3 , “disagree” as 2, and "strongly disagree" as 1 . With 3 as the critical score for the distribution of answers to questions, the data suggests that teacher burnout is moderate to high relative to norms. The Mean=3.79 means that burnout exists. The top scoring item is $2,15,17,21$ and 8 ; and the least five scorings items are 5, 13, 26 and 11. The mean of minimum value is 4.41, showing that the level of burnout are very strong in some detailed aspects.

Most English teachers have a relative strong sense of depersonalization, which is remarkably different from other studies. In comparison, emotional exhaustion and depersonalization are more common. Surprisingly, combined with the results of structural study and table 4-13, the mean of TPI is 4.02 , which is relatively higher than the critical value. While, the mean value of burnout is 3.79 , which represents there are burnout phenomenon among university English teachers. This finding is differing from with other studies. On this basis, the correlations between burnout and TPI are analyzed using Pearson product moment correlations.

Turnover intention. The significant connection between turnover intention and TPI are inspired by the literature review part. The lower the scores, the lower turnover intention. It can be asserted that the level of turnover intention is lower. The mean value is 2.37 , which is lower than the critical value 3 obviously, which means that teachers will not leave their position somehow.

A surprising pattern is explored in the present study. Results of multiple regression analysis highlighted that profession dimensions and turnover intensions interaction predicted the level of TPI, while turnover intensions are predicted by all TPI dimensions.

The correlation between TPI, burnout and turnover intention. As two main section of relational study in the research of TPI, teacher burnout and turnover intention play significant role from the perspective of psychological factors. Teacher burnout in Pearson Correlation is .560**, while Turnover intention is .372**, the 2-tailed values are 1 and $.489 * *$.

There are relatively strong relationships between the three variables. The correlation between TPI and TI is significantly, and correlation between teacher burnout and TPI is not so obvious. The results mean the higher level of TPI, and the lower the level of turnover intention. Unexpectedly, the present study finds there is not obviously negative correlations between the level of TPI and teacher burnout, which is the higher level of TPI, also the relative higher the level of teacher burnout. The current study speculates that it is results from the background of educational internationalization, which will attempt to verify by interview. Furthermore, both of the two parts are agreed to attempt to enhance teachers' professional identity to influence the stability of the teachers' group and to promote teaching efficacy.

Satisfaction. There is a relatively higher level of TPI, which is differing from other researches' findings. There are 15\% English teachers think they are very satisfied with their jobs; and 65\% teachers do not care about this question, they think it is doesn't matter; $20 \%$ teachers are dissatisfied with their job. The results indicate that the level of teachers' job satisfaction is relatively lower.

To probe into the reasons and verify the findings, questions of job satisfaction are involved into 
the interview. 16 participants were selected as the interviewees, considering gender differences. Question item likes "As an English teacher, do you think university English teachers have a higher social position? And what's your colleague' opinion”. Surprisingly, there are 87\% interviewees think university English teachers are having a considerably higher social positions, and $10 \%$ think a relatively higher, other $3 \%$ view a common. The results analysis indicates that most of the university English teachers are satisfied with the profession.

Afterwards, question items like "do you feel stress or pressure as university English teachers? If yes, and what pressure and stress are you facing?" differing with the first question, there are some dissatisfactions they are presented. When facing with some challenges and difficulties, for instance, Mr. Li says "I am responsible for the management of international classes; I feel much stressed when facing with the internationalization of education. Teachers are required more to meet the demanding of teacher education and teaching activities. Some parents are hoping their children to study or work abroad, so they want teachers to cultivate children's international perspective, innovative spirit of their children to adapt to the international life. Some teachers are afraid to eliminate by the society without self-improvement and development. In conclusion, they are feel great pressure sometimes. The same as Mrs. Wang says "new requirements and reformations in the teaching activities”.

That is to say, from traditional perspectives, university English teachers are satisfied with their profession. However, they are dissatisfied when facing with the pressures and stresses. The findings are differing from other researchers partially, which proved that there are obviously positive correlations between TPI and satisfaction. Therefore, hypothesis of the internationalization is the underlying reason attracts attention.

\section{Results and Discussion}

Generally speaking, university English teachers have a relative strong professional identity in the current situation, while the sequencing number are presented as: role value $>$ professional value $>$ professional sense of belonging $>$ professional behavior tendency. In addition, there are no significant differences of TPI in terms of genders, ages, and professional titles. However, there is significant difference in terms of educational backgrounds. According to relational studies, burnout phenomenon is existed among university English teachers, and the inversely correlation between the level of TPI and teacher burnout are no so obviously compared with other researches. Besides, the TPI is negatively correlated with turnover intention significantly and positively with satisfaction. Specifically, the representations are exploring in the following seven aspects in line with the structural studies and relational studies.

\subsection{Results}

\subsubsection{Role values.}

There is relatively higher level of role value throughout. There are no significant differences between male teachers and female teachers and the level of female teachers' professional identity is higher than male teachers. Especially, on the dimension of ages, role value is obviously higher than other three variables. And at the age of 50, it can be seen a significant turning point, and the sense of role values are decreasing sharply. In terms of educational backgrounds, there are no significant differences, and post graduates English teachers own the highest position of role value. In addition, compared with junior colleges educational backgrounds, English teachers with undergraduate's education are undergone relatively lower position. Besides, professional titles are making significant differences of role values.

\subsubsection{Professional value.}

There are no significant differences between male teachers and female teachers and also the level of female teachers' professional identity is higher than male teachers. Besides, the level of professional value is decreased first and then rising, and the age 50, professional value achieves the 
highest level. In terms of educational backgrounds, there are significant differences. Educational backgrounds have a negative effect professional values and emotions, and the teachers with lower education background have stronger TPI than higher educated English teachers. Meanwhile, post graduates English teachers own the highest position of role value. In addition, compared with junior colleges educational backgrounds, English teachers with undergraduate's education are undergone relatively lower position. Besides, professional titles and school levels are making significant differences of role values.

\subsubsection{Professional sense of belonging.}

The tendency of professional sense of belonging is similar to the trend of TPI; there are no significant differences between male teachers and female teachers and also the level of female teachers' professional identity is higher than male teachers. Besides, the same trend as professional value, the level of professional value is decreased first and then rising, and the age 50, professional value achieves the highest level. In terms of educational backgrounds and school levels, there are significant differences. And post graduates English teachers own the highest position of role value. In addition, compared with junior colleges educational backgrounds, English teachers with undergraduate's education are undergone relatively lower position.

\subsubsection{Professional behavior tendency.}

As the lowest level of TPI, the trend of professional behavior tendency is relatively gentle. With terms of genders, educational backgrounds and school levels, the data analysis explore that there are significant differences. Firstly, the level of female teachers' professional behavior tendency is higher than male teachers. And based on the characteristics of primary education and cultural backgrounds, female teachers are more popular. Secondly, the level of professional behavior tendency is decreased first and then rising placid, and the age 50, it achieves the highest level. In terms of educational backgrounds and school levels, there are significant differences. And post graduates English teachers own the highest position of role value. In addition, compared with junior colleges educational backgrounds, English teachers with undergraduate's education are undergone relatively lower position.

\subsubsection{Teacher burnout.}

There is burnout phenomenon among university English teachers $(\mathrm{M}=3.79)$. Details are presented that most English teachers have a relative strong sense of depersonalization, which is remarkably different from other studies. Besides, the inversely correlation between TPI and teacher burnout are not so obviously than other research.

\subsubsection{Turnover intention.}

Turnover intention is much lower than the medium, and English teachers are addressed the stability of teaching profession as common, and there is significantly negative correlation between the level of TPI and turnover intention. And ageing characteristics are significantly.

\subsubsection{Satisfaction.}

The analysis of interview data explores that university English teachers are satisfied with their profession, perspectives from the stability, high social position, relatively high income, winter and summer vacation, and so on. However, they feel stress and pressure.

The research results indicate that there are some good psychological conditions among them, from instance, the relatively high level of TPI, lower turnover intention, relatively job satisfaction. However, there are some issues existing among most English teachers, which will push them stuck in bad situations. Take teacher burnout for example, the high level of burnout will address as triggers for the change of TPI, and push them to leave the position finally. In addition, the lower level of professional behavior tendency, the heavily stress of dissatisfaction, which will do great harmful to the development of teachers. Thus, what are the underlying reasons and how to deal with the issues are making sensations. 


\subsection{Discussions of underlying reasons}

TPI is a contextualized process. According to the results, factors that influence TPI are analyzed as follows.

First of all, two reasons are explored for the relatively higher level of role values. Role value emphasizes the teacher's contribution to the society and others, and self-realization of teachers is ignored relatively. From conventional perspectives, English teachers are regarded as contributed special to the society because of the special English languages. Besides, on the basis of the interview results, the profession of teachers is regarded as stable occupations which possess a high social position, relatively high income, winter and summer vacations. Especially, it is suitable for females. There are more female teachers than males in the present study, and accordingly, the level of role values is relatively higher than other three dimensions in structural studies.

Secondly, professional value of English teacher is determined by education level. Teachers with higher level of education are relatively has a higher level of professional value. To be more specific, the level of teacher professional value to some extent is linked to their comprehensive English language competence. That is, for university English teacher, the English language ability has a direct impact on the level of professional value. However, although English teachers with junior colleges, they have a relatively higher level of English teachers with undergraduates' educations. This is dominated by teachers' psychological activities for lower educational level of teachers are more cherishing the job and to study more in order to avoid losing.

Thirdly, professional sense of belonging is explored the influencing factors as follows. One is depending on school policies. The higher level of schools, the managements are relatively more democratically. English teachers have more chances to express themselves and take part in more issues. In addition, the formation of professional sense of belonging is inextricably linked with their educational courses. The higher level of educational backgrounds means more profession in English teaching field, which will have more right of speech.

Fourthly, professional behavior tendency is addressed the lowest level among the four dimensions. Influenced by conventional views, English is expected to behave as "to death to teaching”. When facing with the internationalization, they do not prepare to deal with it. English teachers' early experience will influence their teaching practices greatly, and they cannot to react and make a change in behavior.

Fifthly, the higher level of burnout is an inversely phenomenon. According to the interview data, the burnout is mainly coming from work stress and the emotional experiences. The educational system within a society is based on knowledge and communication abides by the rules of contemporary and changing society, facing with the ever-changing of course, beliefs, communication, integration emerged by internationalization, English teachers are burnout in emotions and confused in actions, which is in line with the professional behavior tendency.

Sixthly, the lower level of turnover intention. Although encountering on the numerous pressures and stress when facing with the contradictions and conflicts, English teachers are no do want to leave this stable and reputational position. In addition, there is a negative relationship between age and turnover intention. When teachers are becoming elder, they will hold the profession more tightly.

Seventhly, Satisfaction. From the conventional perspectives, English teachers are satisfied with their profession eagerly, especially, the good benefits the profession brings. Towards the internationalization of education, they are enjoyed the convenience of the learning methods, the need of English, and the need of English teachers. On the other hand, they are avoiding to bearing the new changing and requirements. When faced these, they do not consider how to deal with, so they feel dissatisfied. Besides, after making a reference of the interview data, the results indicate that for self-improving to satisfy the job demanding, English teachers with junior college educational backgrounds own a higher level of job satisfaction. 


\section{Conclusions: Improving the Level of TPI}

On the basis of the aforementioned research results together with the theoretical foundations, several conceivable ways to improve the degree of TPI among university English teachers are suggested in line with to improving the level of TPI, reducing burnout and decreasing job dissatisfactions among teaching professionals from the following seven aspects accordingly.

\subsection{Role values.}

A deep change approach in reforms involves altering underlying goals and beliefs that underpin the existing ideology. Departing from reasons of conventional social expectations, to improving the level of university English teachers' role values can be preceding with self-realization. On the basis of SCCT, the judgments of one's capability to organize and execute courses of action required to attain designated type of performances. For English teachers, whatever female and males, self-efficacy is very significant and to improving self-efficacy is dependent on personal performance accomplishments. English teachers, in the frontier of education and the impingement of internationalization, are required high role values. However, competence in content knowledge and pedagogy are expected as autonomous and reflective. Considering the significant differences in terms of ages, the conception of "lifelong learning" are deserved more attention to spread among English teachers.

\subsection{Professional roles.}

The comprehensive English language competence is explained as the main underlying reason. Professional knowledge, as the precondition for teachers strive to improve their capability in the knowledge society, entails teachers to become aware of their professional identity. Therefore, the encouragement to continue learning and developing professionally from schools and educational institutes are functioned effectively and directly. On the other hand, teachers are suggested to further education to enrich and update their knowledge in the special internationalization trend, in where, knowledge is updated at breakneck speed and the past learned knowledge is probably outdated and inapplicable. What is more, according to the theories of educational internationalization and identity, new professionalism entails the acceptances of new roles from the part of teachers, such as teaching facilitators and co-participants in the learning process, and linked to be equipped with up-to date teaching techniques and use modern language teaching materials, they should use technology together with other materials as instruments for learning and facilitate with the changing. For instance, Mobile learning and Massive Open On-line Courses (MOOCs). Mobile learning enables learning anytime and anywhere, which has furthered prominence in various education sectors. MOOCs, as important platform for expanding accessibility and online education innovation, generated interest to transform the landscape of education. Meantime, policy makers and leader teachers grant more to developing up-to-date EIL materials and encouraging self-improving to help to constructing university English teachers’ professional values.

\subsection{Professional sense of belonging.}

Educational backgrounds and school levels are emerged significant correlations of professional sense of belonging on the basis of the reason analysis. It is recommended educational institutes to encourage inclusive policy-making and increased diversity presents challenges on educational policy options, which will influence and shape identity directly. More inclusive processes of consultation on the key policy issues are essential to constructive citizenship education in a diverse world. To improve teachers' sense of belonging and enhance teachers' professional identity, schools are recommended to make changes in management. For instance, improve school management, create democracy harmonious school environment and respect teachers. All these ways maybe worked to leading them to a higher level of professional sense of belonging.

\subsection{Professional behavior tendency.}

According to the reason analysis and outcome expectations of SCCT, English teachers are more 
likely to construct their TPI if they envision favorable outcomes resulting from teaching behavior, and less likely to decrease their passion to shape TPI if they anticipate negative outcomes. Besides, environment factors can influence the cognitive-person variables. Therefore, for English teachers, what outcomes you want, which behavior tendency you behaved, to make educational choice goals is necessary [13]. Especially, when facing the contradictions and conflict emerged from internationalization, they are confused to deal with urgently. Therefore, educational institutes are carried out to training teachers with the introduction of internationalization, and help them to recover from the confusion. In addition, teaching stage models indicate that teachers will display different characteristics in different teaching stages. Educational institute is better to paying more attention to the development of teachers.

\subsection{Relatively higher level of burnout.}

The burnout is mainly coming from work stress and the emotional experiences. English teachers should learn more about the internationalization of education and inspired from its characteristics and requirements, so as to improving the social adaptability [14]. Besides, schools can attempt to organize more teachers training classes and also providing more chance to international visiting activities, which can help them adapting and knowing more about the internationalization, and the cooperative efforts are combined to concert the contradictions. In addition, greater awareness of the pressures should be placed on public financing of educational and psychological training systems. To a certain extent, to ensure greater accountability in the investment of public resource, find ways to supplement them through greater fiscal capacity, increase the investment of English education and improve teachers' welfare, is precondition to improve education quality and improve teachers' material and spiritual conditions.

\subsection{Lower level of turnover intention.}

This is a good condition for current situations of TPI, which deserve to commendable. As considering the significant differences in terms of ages, schools' managements shall provide special accommodations to the new comer teachers in order to helping them have a good start.

\subsection{Relatively dissatisfaction.}

Tightly linked with the level of burnout, pressure, turnover intention and so on, the psychological factors and positive attitudes of teachers are curial. Teachers will have inner power to reverse the deprofessionalization, turnover intensions and burnout of teachers potentially [15]. Continuous and self-reflection are significantly, treat success and failures peacefully and push to make progress gradually [16]. Teachers must have confidence to conquer the troubles.

In addition, making reasonable measures to develop teachers' potential, helping them to realize individual value possibility are recommended. Let teachers get some positive professional experiences. Enhance their professional identity. Recall the essential role that educators play in ensuring learning throughout life and beyond formal education systems. The importance of this role is evidence in the growth of training program worldwide for educators working in a variety of non-formal and informal settings. Teacher training at all level - from the most general to the most specialized - must better integrate the very essence of the transdisciplinary spirit: an interdisciplinary approach that can enable teachers and professors to lead to creativity and rationality.

It is not surprising that process of change, especially one that affects a whole system of educational practices, has encountered difficulties and sometimes even failure. The emergence of new economic powers and financial crisis has contributed to changing relations between countries; cooperation has been playing an increasing important role in international development. As countries face increasing similar difficulties (unemployment, inequalities, climate change, and tec.), the fact that appropriate jobs are becoming scarcer is causing increasing frustration among families and young graduates around the world. Rising levels of educational attainment among youth, and workers more generally, are leading to increased competition for jobs. There is now a call for schools and integration as essential features of the future development agenda. This paradigm shift 
compels to think in terms of shared responsibilities for a shared future.

\section{Acknowledgements}

The authors are grateful to Shaanxi Higher Education Teaching Reform Project "Construction and Realization of KACIA Curriculum System of College English (Project No. 17BZ033), and Yan'an University Postgraduate Teaching Reform Project "The Three Dimensional Targets and Realization of Teaching and Research for Master of Education Programs”.

\section{References}

[1] Huang. F. T. Internationalization of curricula in higher education institutions in comparative perspectives: Case studies of China, Japan and the Netherlands [J]. Higher Education, 2006, (1):21-39.

[2] McGowen KR \& Hart LE. Still different after all these years: Gender differences in professional identity formation [J]. Professional Psychology: Research and Practice,1990, 21(2): 118-123.

[3] Erikson, E. H. Identity, Youth and Crisis [M]. New York: W. W. Norton \& Company. 1968:35-36.

[4] Beijaard, D. Meijer, P. C. \& Verloop, N. Reconsidering research on teachers' professional identity [J]. Teaching and Teacher Education, 2004, 20 (2):107-128.

[5] Day, C.\& A. Kington. Identity, well-being and effectiveness: The emotional contexts of teaching [J]. Pedagogy, Cultural and Society, 2008, 16(1):7-23.

[6] Ajayi, L. How ESL teachers' sociocultural identities mediate their role identities in a diverse urban school setting [J]. Urban Review: Issues and Ideas in Public Education, 2011,12 (6):654-680.

[7] Lent, R. W. et al. Toward a unifying social cognitive theory of career and academic interest, choice, and performance. Journal of Vocational Behavior. 1994, 45 (1):79-122.

[8] Zembyls, M. Emotions and teacher identity: A post-structural perspective [J]. Teachers and teaching: Theory and Practice, 2003, 9 (3):213-238.

[9] Howard, S. \& Johnson, B. Resilient teachers: Resisting stress and burnout [J]. Social Psychology of Education, 2004, 7 (5):399-420.

[10] Ference, T. Exploring the professional role identities of identities of experiences ESL teachers through reflective practice [J]. System, 2011, 39 (1): 54-62.

[11] Tusi, A. B. M. Complexities of identity formation: A narrative inquiry of an EFL teacher [J]. TESOL Quarterly, 2007, 41(6):657-680.

[12] Clark, M. Language Teacher Identities: Co-constructing Discourse and Community [M]. Clevedon: Multilingual Matters, 2008:64-65.

[13] Luthans, F.et al. The psychological capital of Chinese workers: Exploring the relationship with Performance [J]. Management and Organization Review, 2010, 1 (2): 249-271.

[14] Maslach, C. Job burnout: New directions in research and intervention [J]. Current Directions in Psychological Science, 2003, 12 (5): 89-192.

[15] Ross, J. A. \&Bruce, C. D. Teacher self-assessment: a mechanism for facilitating professional growth [J]. Teaching and Teacher Education, 2007, 23(2): 146-159.

[16] Smit, B. E. Fritz \& V. Mabalance, A conversation of teachers: In search of professional identity [J]. The Australian Educational Researcher, 2010, 37 (1): 93-106. 